\title{
A Produção e a Utilização de ebooks Interativos e Multimídia em EaD
}

\author{
Eduardo Henrique M Lima ${ }^{1}$, José M E Bidarra ${ }^{2}$ \\ ${ }^{1}$ Universidade Federal de São João del-Rei (UFSJ) \\ Campus Centro-Oeste - Divinópolis - MG - Brasil \\ ${ }^{2}$ Departamento de Ciência e Tecnologia - Universidade Aberta de Portugal \\ Lisboa, Portugal \\ eduardo.henriquedufsj.edu.br, jose.bidarra@uab.pt
}

\begin{abstract}
In this work we present a proposal for a doctoral research on the production and the use of interactive and multimedia ebooks in education. They are considered in the study of the detailed evidence of m-learnning with the prospects based on cyberculture and media culture studies. Three main research strategies are being used: literature and document review; data collection on a case in Brazil; development and implementation of a prototype interactive and multimedia ebook in distance education. We hope to contribute to the list of investigations that can evaluate and propose artifacts formats and interactive media with educational potential in line with the current context.
\end{abstract}

Resumo. Neste trabalho apresentamos uma proposta de pesquisa de doutorado sobre a produção e a utilização de ebooks interativos e multimídia na educação. São considerados no estudo os elementos circunstanciados da m-learning, com as perspectivas delineadas com base em estudos da cibercultura e da cultura midiática. Estão sendo utilizadas três estratégias principais de investigação: revisão bibliográfica e documental; recolha de dados sobre um caso no Brasil; elaboração e aplicação de um protótipo de ebook interativo e multimídia em EaD. Esperamos contribuir com o rol de investigações que possam avaliar e propor formatos de artefatos e meios interativos com potencial educativo em consonância com o atual contexto.

\section{Introdução}

O processo de desenvolvimento e de expansão das Tecnologias Digitais de Informação e Comunicação - TDIC - é irreversível, a cada dia novos aplicativos, tecnologias e sistemas são produzidos, e a informatização amplia a sua presença em todos os setores da sociedade. Os equipamentos/dispositivos digitais que apresentam diferenciais significativos nesse processo são os smartphones e os tablets, que além de intensificar o fenômeno da mobilidade, estão diretamente relacionados às transformações apontadas em teorias da cibercultura.

Tais tecnologias potencializam as nossas ações nos mais diversos segmentos, indicando possibilidades de renovação/reconfiguração ou substituição daquilo que já fazemos e da forma que fazemos [Lemos 2003]. Entendemos que a educação representa um espaço fundamental para fazer com que as pessoas possam ser inseridas de forma consciente e 
crítica nessa cultura, que tenham a oportunidade de acesso e de compreensão acerca da necessidade de apropriação das tecnologias digitais em sua realidade.

O profissional da educação deve assumir o compromisso de repensar sua dinâmica considerando não somente as mudanças constatadas, mas a necessidade $\mathrm{e}$ as possibilidades do uso das TDIC nas práticas pedagógicas em um cenário favorável às transformações.

A integração de dispositivos digitais que explorem especialmente a mobilidade, com recursos dinâmicos e interativos, em propostas pedagógicas nos parece coerente e pertinente. Uma das possibilidades de ampla utilização dessa perspectiva de mobilidade e interatividade na educação/aprendizagem são os ebooks.

Nesse sentido, pretendemos com esta proposta de investigação explorar o potencial de implementação de um projeto voltado para a elaboração e a utilização de ebooks interativos e multimídia para fins educativos, procurando discorrer sobre os elementos que compõem ou que possam ser considerados nessa concepção.

Entendemos que existe um grande potencial de utilização de ebooks interativos e multimídia em propostas de e-learning por tratar-se de um recurso em consonância com o contexto sociocultural em que estamos inseridos, do envolvimento de grande parte dos alunos com as tecnologias digitais e do cenário de mobilidade que se mostra em expansão. No entanto, existe ainda a necessidade de se desenvolver estudos e abordagens apropriadas, que contemplem a elaboração e a aplicação em processos de ensino e aprendizagem, especialmente em cursos na modalidade a distância.

\section{Objetivo}

O tema dessa pesquisa está relacionado a apropriação e uso das tecnologias digitais de informação e comunicação na educação. Precisamente, como objetivo geral, pretendemos realizar um estudo que viabilize compreender o potencial de utilização de ebooks interativos e multimídia em propostas de ensino e aprendizagem em cursos na modalidade e-learning, dentro de conceitos e perspectivas apontadas pela m-learning.

\section{Enquadramento Teórico}

Neste estudo procuramos considerar os elementos circunstanciados da m-learning em propostas de utilização de ebooks na educação, especialmente em e-learning, com as perspectivas delineadas a partir das transformações que estamos vivenciando com base em estudos da cibercultura e da cultura midiática, com os avanços marcantes e repleto de possibilidades da tecnologia móvel.

\subsection{Cibercultura e Cultura Midiática: implicações para mudanças na educação}

A cibercultura é uma forma sociocultural que modifica hábitos sociais, práticas de consumo cultural, ritmo de produção e distribuição da informação, criando novas relações no trabalho e no lazer, novas formas de sociabilidade e de comunicação social a partir do desenvolvimento e do uso das tecnologias digitais [Lemos 2003; Lèvy 1999].

Diante de um cenário com amplas possibilidades e necessidades de integração das mídias em vários aspectos nos espaços individuais, sociais e profissionais, as escolas e universidades são chamadas a repensarem seus compromissos e propostas pedagógicas. 


\section{CBIE-LACLO 2015}

Anais dos Workshops do IV Congresso Brasileiro de Informática na Educação (CBIE 2015)

Os modelos tradicionais de ensino ainda predominam nas escolas, as aulas centradas nos professores precisam ser substituídas por propostas que levem em consideração as mudanças dos alunos desse atual contexto, que falam na linguagem digital dos computadores, videogames e internet [Mattar 2010].

A cultura midiática, imbricada nos aspectos relacionados à cibercultura, envolve questões pertinentes à mobilidade, portabilidade e conectividade, a produção e compartilhamento de informações, do acesso e inclusão digital/social/cultural, da cultura da participação, entre outros. Vivemos um contexto de grandes possibilidades de autoria e maior participação social, político e cultural [Lemos e Lèvy 2010].

No entanto, é fundamental o processo de reflexão e de questionamento para que essas possibilidades sejam efetivas e qualitativas. Temos que refletir sobre como "essa nova cultura vem dialogando ou não com a educação e, consequentemente, com a prática pedagógica que vem sendo realizada em nossas salas de aula" [Leite 2011, p. 64].

Nessa perspectiva, o ebook interativo e multimídia pode apresenta-se como potencial representativo em propostas de reconfiguração no contexto educacional, como parte dos elementos que podem compor esse novo cenário.

\section{2 e-Learning e m-Learning como Fenômenos da Cibercultura}

Com as novas exigências educativas frente ao cenário informacional e tecnológico, o $e$ learning apresenta-se como um modelo de Ensino a Distância $(\mathrm{EaD})$ com significativa relevância. Trata-se de um suporte de informação e comunicação com possibilidades efetivas ao acesso, desenvolvimento e disponibilização de conteúdos e estratégias em processos de ensino e aprendizagem.

$\mathrm{O}$ e-learning, compreendido como formas diversificadas de aprendizagem via internet por meio das TDIC, surge como uma nova perspectiva para a $\mathrm{EaD}$, um estágio para mudanças ainda mais representativas na práxis educativa, com um conjunto de funcionalidades que abre oportunidades para mediar e organizar conteúdos e propostas de trabalhos voltados para a construção do conhecimento [Inocêncio 2012].

Com os novos dispositivos digitais e a possibilidade da mobilidade, o e-learning passa a ter outros desafios para continuar expandindo e agregando novos recursos nos processos de ensino e aprendizagem, a busca por mais inovação.

A partir de proposições que considerem os pressupostos de aprendizagem móvel em $\mathrm{EaD}$, da organização, desenvolvimento e disponibilização de Ambiente Virtuais de Aprendizagem (AVA) configurados em ambientes e dispositivos móveis [Weber e Santos 2013; Ribeiro et al 2013], nossa proposta faz referência ao conteúdo, aos aspectos e questões relacionadas ao desenvolvimento e utilização de recursos/artefatos móveis que possam contribuir com o processo de ensino e aprendizagem. Mais precisamente sobre a utilização de ebooks interativos e multimídia na abordagem de conteúdos em cursos na modalidade e-learning, procurando argumentar sobre como a abordagem de conteúdos pode ser potencializada com a mobilidade e a flexibilidade através de ebooks interativos e multimídia.

Diante das possibilidades de uma estrutura de mobilidade, a aprendizagem móvel ou mobile learning (m-learning), faz referência ao uso dos dispositivos digitais móveis e 


\section{CBIE-LACLO 2015}

Anais dos Workshops do IV Congresso Brasileiro de Informática na Educação (CBIE 2015)

portáteis em atividades de ensino e aprendizagem. De acordo com Weber e Santos (2013), não existe consenso sobre o conceito de aprendizagem móvel, mas assumimos nesta proposta a caracterização da m-learning como forma de promoção de maior controle e autonomia sobre a própria aprendizagem, a aprendizagem em contexto, a continuidade e conectividade, além da espontaneidade e oportunidade [Saccol, Schlemmer e Barbosa 2011].

No atual cenário, podemos constatar a ampliação e a flexibilização tanto do acesso quanto da utilização de dispositivos digitais móveis para diversas finalidades. Em relação à educação, os aspectos técnicos devem ser amparados e fundamentados em concepções epistemológicas que permitam compreender as reais condições e precisões de apropriação com finalidades pedagógicas.

Entendemos que o e-learning representa um avanço quanto ao uso das TDIC na educação, com grande potencial e possibilidades de expansão, mas que se encontra em um estágio ainda inicial no Brasil [Weber e Santos 2013]. Nesse sentido, considerando a facilidade de acesso crescente em termos de recursos e utilização de dispositivos digitais, as inovações que podem ser promovidas por meio da mobilidade, representam novas possibilidades para o e-learning, ampliando seu potencial e abrindo novas perspectivas nesse cenário em expansão.

\section{3 ebooks (interativos): contexto, desenvolvimento e possibilidades na educação}

Desde a década de 1990 existia o interesse na criação de livros eletrônicos, de ebooks, assim como em dispositivos que permitiriam a leitura para esse tipo de produção. Em 2007, com o lançamento do Kindle, da Amazon, iniciaram os esforços para o desenvolvimento e a utilização de um novo tipo de mídia. No entanto, somente a partir de 2010, com o lançamento do iPad da Apple, os ebooks ganharam um novo meio de leitura, ampliando suas possibilidades com os recursos interativos e de conexão.

O termo ebook é utilizado desde a década de 1970, com o Projeto Gutemberg, voltado para a digitalização e disponibilização de livros de domínio público na internet [Duarte 2011]. A primeira plataforma de criação e publicação de ebooks interativos só foi lançado em 2011 (Push Pop Press), com o ebook "Our Choice". Entretanto, "Five Little Pumpkins" é considerado o primeiro ebook interativo com a experiência de leitura imersiva, portanto, pioneiro nessa proposta.

Com o desenvolvimento de tecnologias que facilitam a leitura em telas, com os avanços e a ampliação na comercialização de formatos específicos, além dos dispositivos digitais móveis como tablets e smartphones com preços mais acessíveis, os livros eletrônicos vêm ganhando cada vez mais atenção e espaço.

Os ebooks apresentam diversos formatos, com especificidades em suas características e nos modos de apresentação do conteúdo. O principal formato de ebooks na atualidade é o ePub (Eletronic Publication), "arquivo baseado em padrões abertos como o HTML, XML e CSS, originalmente chamado de Open Ebook" [Duarte 2011, p. 10]. A versão mais recente do ePud é o ePub3, que pode ser definido como formato para a utilização de ebooks para consumidores finais, para distribuição global.

Os livros eletrônicos interativos têm mais do que palavras e dados, dão a oportunidade de fundir texto, animação e interação. Livros interativos, que possam ser utilizados em 
diferentes plataformas, representam possibilidades expressivas para combinar uma série de expedientes em abordagens pedagógicas, além da integração de disciplinas e da disponibilização de informação [Roosen 2012].

Podemos afirmar que a utilização de dispositivos digitais móveis em processos de ensino e aprendizagem representa uma possível ampliação das práticas pedagógicas. No entanto, não deixa de ser um grande desfio desenvolver metodologias e/ou recursos que representem melhorias nos resultados de aprendizagens e mudanças na educação [Lima 2011; Bidarra et al 2012].

Será fundamental refletir e ampliar o entendimento acerca dos aspectos identificados neste primeiro momento, em especial relativos à mobilidade e o conceito de narrativas digitais em contexto de educação visando o desenvolvimento de propostas pedagógicas em consonância com práticas crescentes de utilização de dispositivos digitais, pois vem se tornando uma necessidade e ganhando cada vez mais espaço [Ribeiro et al 2013; Weber e Santos 2013].

\section{Desenvolvimento Metodológico}

Neste estudo propomos o desenvolvimento de abordagens de investigação quanti-quali, que permitem a utilização de instrumentos e procedimentos múltiplos de coleta e análise de dados em contextos diversos [Creswell 2007]. As práticas adotadas estão relacionadas aos procedimentos definidos para o Estudo de Caso, com perspectivas delineadas para Pesquisa Exploratória e Descritiva

\subsection{Revisão Bibliográfica e Documental}

Quanto à revisão bibliográfica e documental, visando o enquadramento e a sustentação do estudo, estão sendo realizados levantamentos com o objetivo de identificar e correlacionar estudos significativos que compõem parte dos aspectos epistemológicos pertinentes a abordagem dessa proposta, considerando o desenvolvimento das definições que pretendemos acerca de questões de apropriação de ebooks interativos em práticas educativas, além da utilização de dispositivos digitais móveis em cursos na modalidade a distância.

\subsection{Recolha e Análise de Dados Sobre um Caso no Brasil}

O estudo de caso foi definido por tratar-se de questões vinculadas a um evento com foco em fenômenos contemporâneos dentro de um contexto de vida real. Por ser um método eclético, o estudo de caso, que pode ser trabalhado por meio das mais variadas técnicas e de métodos que facilitam a compreensão do fenômeno a ser estudado [Oliveira 2007].

Nesse sentido, estão sendo realizados levantamentos a partir de questionários mesclados, com perguntas abertas e fechadas, visando explorar e descrever sobre a apropriação e a utilização de recursos/ferramentas e dispositivos digitais móveis em processos de ensino e aprendizagem em $\mathrm{EaD}$. Os questionários estão sendo aplicados aos professores, alunos e tutores participantes dos cursos de pós-graduação do Núcleo de Educação a Distância da Universidade Federal de São João del-Rei (NEAD/UFSJ). 
Esperamos, como parte dos objetivos dessa proposta, compreender as características dos cursos de pós-graduação do NEAD/UFSJ (recursos, modos de interação, desenvolvimento, abordagem e disponibilização dos conteúdos, etc.), além das formas como professores, alunos e tutores desses cursos utilizam os dispositivos digitais móveis em práticas de ensino e aprendizagem.

\subsection{Desenvolvimento, Aplicação e Avaliação de um Artefato Digital em e-learning}

Posteriormente será desenvolvido e aplicado um modelo de ebook interativo e multimídia voltado para propostas de ensino e aprendizagem em EaD. Será realizada uma pesquisa buscando descrever o contexto em que ocorrerá a aplicação, avaliar essa intervenção e obter maior clareza no conjunto de resultados a partir desta. Pretendemos com essa estratégia compreender os modos de elaboração e utilização de ebooks interativos e multimídia em abordagens pedagógicas em cursos na modalidade a distância, explorar as potencialidades de um artefato digital relacionado com parte da matéria no contexto educativo em e-learning - (as etapas da elaboração e aplicação do artefato estão discriminadas na Figura 1).

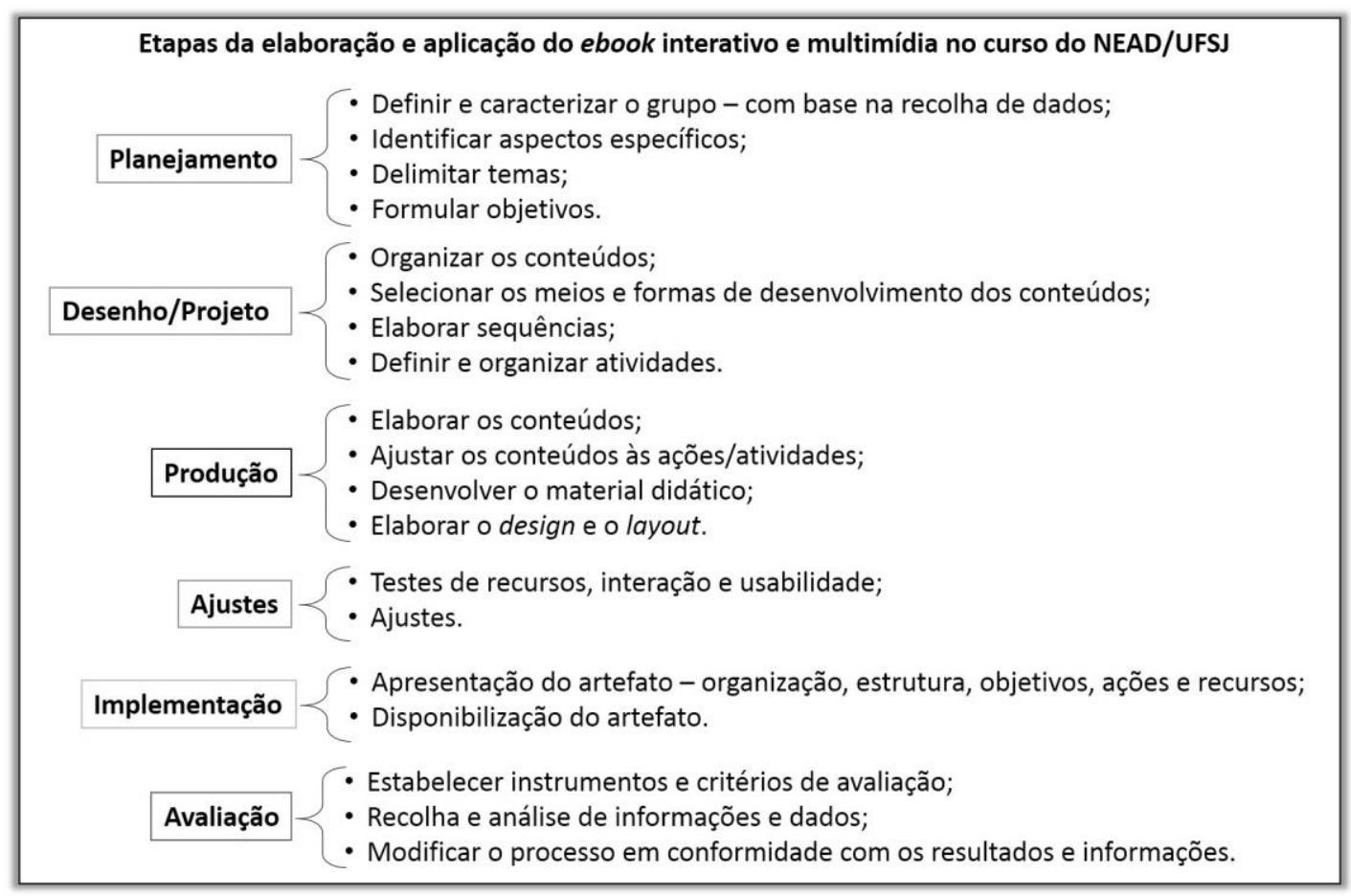

\section{Figura 1: Etapas de elaboração e aplicação do ebook interativo e multimídia no curso do NEAD/UFSJ}

Estão sendo adotados softwares abertos e livres no desenvolvimento do ebook interativo e multimídia, voltado para a plataforma Android, que é a mais utilizada em dispositivos móveis no Brasil. Como parte da fundamentação teórico-metodológica, as teorias do design instrucional serão consideradas na elaboração e sistematização do conteúdo de matemática que será abordado nesta terceira etapa da pesquisa. O conteúdo será definido em momento oportuno - após análise dos dados do estudo de caso (e contará com a participação de professores do curso de pós-graduação em matemática do NEAD/UFSJ), 
CBIE-LACLO 2015

Anais dos Workshops do IV Congresso Brasileiro de Informática na Educação (CBIE 2015)

onde o artefato será aplicado. A figura 2 apresenta as premissas da estrutura e organização do ebook interativo e multimídia.

O ebook interativo e multimídia, após as etapas de produção e desenvolvimento, e os devidos testes de funcionalidade, será disponibilizado para os alunos do curso de pósgraduação em matemática do NEAD/UFSJ para aplicação na abordagem de um conteúdo específico do curso. Em um segundo momento, os alunos serão convidados a participar de um inquérito com questões que permitirão a análise e avaliação do artefato a partir dos seguintes critérios: usabilidade, apreensibilidade, inteligibilidade, atratividade, eficiência e adequação.

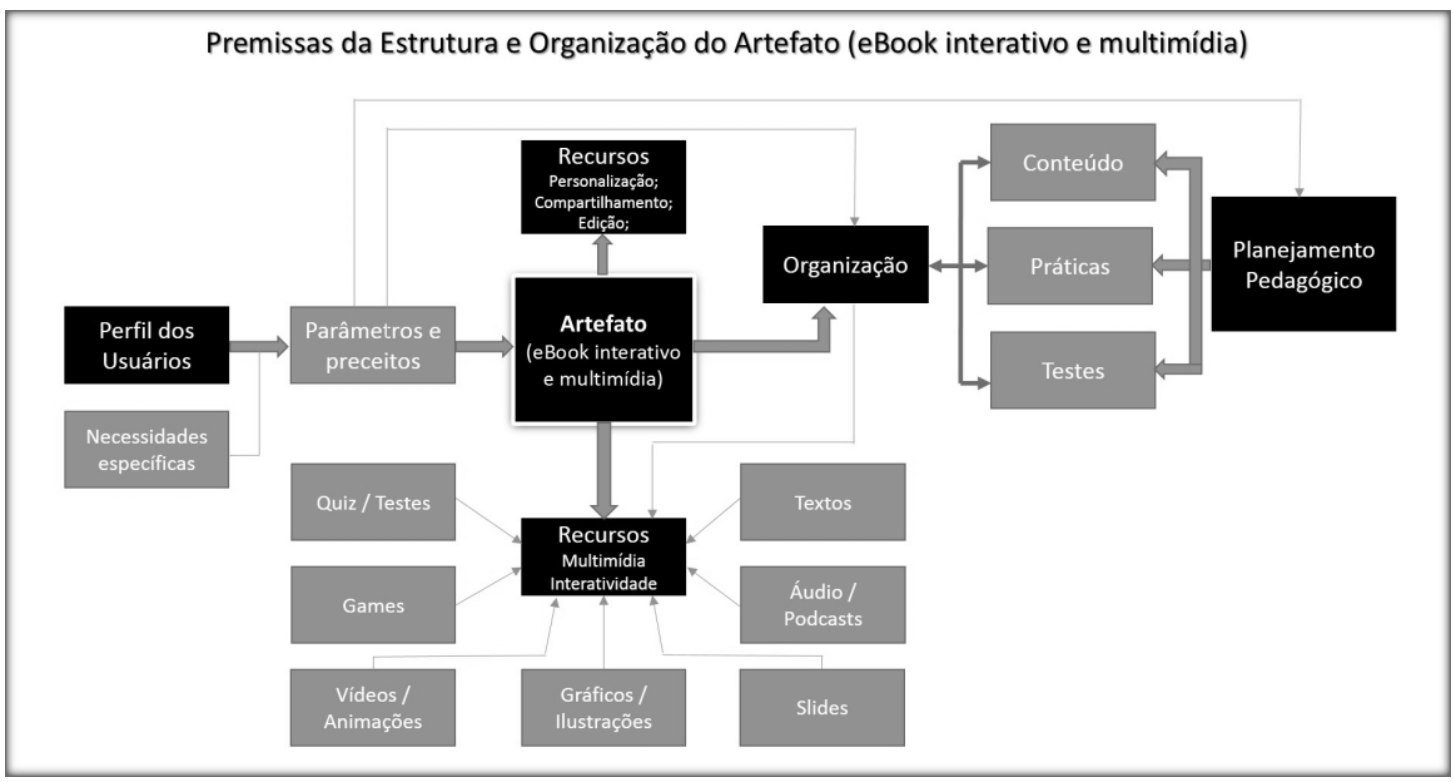

Figura 2: Premissas da Estrutura e Organização do Artefato

\section{Considerações}

O tema apresentado neste trabalho está inserido em um campo de discussão que vem ganhando espaço e sendo desenvolvido de forma profícua na contemporaneidade. São pesquisas que ampliam as possibilidades de reflexão, questionamento e entendimento, abrindo novos espaços para intervenções e articulações, envolvendo as áreas da educação e das tecnologias.

Nosso envolvimento com propostas mais coerentes com os processos de transformações que estamos vivendo, dentro desse contexto da cibercultura, é fundamental para as mudanças na educação. Mas essas mudanças não podem ficar restritas ao uso instrumental das tecnologias e/ou dos recursos e dispositivos digitais, devemos compreender de fato o que está acontecendo, as relações e perspectivas culturais, políticas e sociais a partir dos avanços das novas tecnologias, para que sejam realizadas com responsabilidade, pertinência e criticidade.

Pretendemos com este estudo explorar as possibilidades da educação móvel em cursos na modalidade e-learning. Ainda que em fase experimental e inicial, a adequação e utilização de recursos didáticos em dispositivos móveis é uma tarefa complexa, mas que 


\section{CBIE-LACLO 2015}

Anais dos Workshops do IV Congresso Brasileiro de Informática na Educação (CBIE 2015)

terá nesta proposta a oportunidade de novas reflexões e entendimentos sobre perspectivas mais apropriadas em processos de ensino e aprendizagem na cibercultura.

\section{Referências}

Bidarra, J., Figueiredo, M., Valadas, S., Vilhena, C. (2012). O gamebook como modelo pedagógico: desenvolvimento de um livro interativo para a plataforma iPad. Comunicação publicada nas atas da 6th International Conference on Digital Arts ARTECH 2012, Faro, 7- 9 de novembro de 2012.

Bidarra, J., e Natálio, C. (2014). Ebook Multimédia: o próximo capítulo na divulgação cultural? Comunicação publicada nas ata da $2^{\circ}$ Encontro sobre Jogos e Mobile Learning. Braga: CIEd.

Creswell, J. W. Projeto de Pesquisa: métodos qualitativo, quantitativo e misto. Tradução Luciana de Oliveira da Rocha. 2. Ed.. Porto Alegre: Artmed, 2007

Duarte, M. (2011). eBook: desvendando os livros feitos de pixels. Brasilia/DF: Pagelab.

Inocêncio, M. (2012). O e-learning: uma prática pedagógica desafiadora na Uni-CV. Educação, Formação e Tecnologias, 33-46. Obtido de Educação, Formação e Tecnologias: disponível a partir de http://eft.educom.pt.

Leite, L. (2011). Mídia e a Perspectiva da Tecnologia educacional no processo pedagógico contemporâneo. Em W. Freitas (org.), Tecnologia e Educação: as mídias na prática docente. Rio de Janeiro: Wak.

Lemos, A. (2003). Cibercultura: alguns pontos para compreender a época. Em A. Lemos, e P. Cunha, Olhares sobre a cibercultura. Porto Alegre: Sulinas.

Lemos, A., e Lèvy, P. (2010). O futuro da internet: em direção a uma ciberdemocracia planetária. São Paulo: Paulus.

Lima, M. (2011). Educação na cibercultura: novas possibilidades para o ensinoaprendizagem, Revista Educação e Cultura Contemporânea, Vol. 8, n. 16, em $<$ http://revistaadmmade.estacio.br/index.php/reeduc/article/view/169/142>, última consulta em 14.11.2012.

Mattar, J. (2010). Games em educação: como os nativos digitais aprendem. São Paulo: Pearson.

Oliveira, M. M. de. Como fazer Pesquisa Qualitativa. Petrópolis, RJ: Vozes, 2007.

Ribeiro, R. A., Spilker, M. J., Mandaji, M., Silva, R. K., Terçariol, A. A. L., Mengalli, N. M., Camas, N. P. V. (2013). Educação e Mobilidade: Perspectivas para Integração de Tecnologias Móveis ao Currículo.LE@D - Laboratório de Educação a Distância e Elearning - Comunicações congressos, conferências, seminários / Communications : [153] em <http://hdl.handle.net/10400.2/3099>, última consulta em 10.03.214.

Roosen, C. (2012). The Renaissance of the Interactive Book. Obtido de UX Magazine: http://uxmag.com/articles/the-renaissance-of-the-interactive-book 
CBIE-LACLO 2015

Anais dos Workshops do IV Congresso Brasileiro de Informática na Educação (CBIE 2015)

Saccol, A., Schlemmer, E., e Barbosa, J. (2011). m-learning e u-learning: novas pespectivas da aprendizagem móvel e ubiqua. São Paulo: Pearson Prentice Hall.

Weber, A. e Santos, E. (2013). Educação Online em tempos de mobilidade e aprendizagem ubíqua: desafios para as práticas pedagógicas na cibercultura. Revista EDaPECi. São Cristóvão (SE) v.13. n. 2, p. 168-183. 